\title{
LA REVOLUCIÓN GRIEGA DE 1821. EI PRECURSOR RIGAS VELESTINLÍS
}

\author{
Miguel Castillo Didier \\ Universidad de Chile. Chile
}

Resumen: La Revolución Griega de 1821 presenta varias peculiaridades, una de las cuales es la de la su preparación, en la cual confluyeron factores muy diversos. Entre ellos está la influencia de las posiciones ideológicas de los distintos precursores, que contribuyeron a crear el clima prerrevolucionario. Materia de estudio y discusión son los aportes de figuras tan distintas como Eugenio Vúlgaris (1716-1806), Rigas Velestinlís (1757-1798) y Adamandios Koraís (1748-1833) y otros. En este artículo se estudia la figura del protomártir Rigas.

Palabras clave: Revolución Griega - Rigas Velestinlís

\section{THE GREEK REVOLUTION OF 1821. THE PRECURSOR RIGAS VELESTINLÍS}

\begin{abstract}
The Greek Revolution of 1821 presents several peculiarities, one of which is its preparation, in which very different factors converged. Among them is the influence of the ideological positions of the different precursors, which contributed to creating the prerevolutionary climate. The subject of study and discussion are the contributions of such different figures as Eugenio Vúlgaris (1716-1806), Rigas Velestinlís (1757-1798) and Adamandios Koraís (1748-1833) and others. This article studies the figure of the Protomartyr Rigas.
\end{abstract}

Keywords: Greek Revolution - Rigas Velestinlís

Recibido: 10.12.2020 - Aceptado: 15.2.2021.

Correspondencia: Miguel Castillo Didier

Email: micastilgriego@gmail.com

Profesor titular Universidad de Chile 


\section{La Revolución Griega}

T a Revolución Griega de 1821, que dio nacimiento al moderno estado griego, ha sido calificada como una "revolución excepcional". Lo es en diversos sentidos, sin duda. Nacida en pleno dominio de la Santa Alianza, parecía no tener destino. Las disensiones entre los patriotas, que afloraron desde el primer momento y que llegaron a tener la forma de dos guerras civiles, dentro de la desigual contienda con el Imperio Otomano, la pusieron al borde del fracaso. El espíritu anárquico que culminó con el asesinato del Ioanis Kapodistrias, el primer Gobernante, tuvo por resultado la imposición de un rey extranjero y de un régimen absolutamente opuesto al ideal democrático de varios de los precursores. Es excepcional asimismo por haber despertado en Europa un movimiento de solidaridad nunca visto con una causa. El filohelenismo, que venía forjándose especialmente en Alemania desde la segunda mitad del siglo XVIII, toma variadas formas, entre otras la marcha a tierra griega de muchos combatientes. Su figura más ilustre es, sin duda, Lord Byron, que muere en Mesolonyi en abril de 1824.

La Asamblea Nacional de Trezena había elegido a Kapodistrias como Gobernante el 2/14 de abril de 1827, pero su gobierno efectivo comenzó en 1828. El 3 de febrero de 1830, el Protocolo de Londres consagra la independencia de un muy pequeño estado griego, devastado por la guerra. El 27 de septiembre de 1831 cae asesinado Kapodistrias. La completa anarquía que sigue al crimen, "termina" con la entronización el 6 de febrero de 1833 del rey Otón, un príncipe bávaro.

\section{La Revolución}

El primer estallido de la Revolución se produjo en Moldovalaquia, en febrero de 1821, donde el príncipe Alejandro Ipsilandis, hasta entonces edecán del zar de Rusia, y que se había incorporado a la Filikí Hetería el año 1820, pretendió iniciar un movimiento al que él pensaba se unirían los otros pueblos tiranizados por el Imperio Otomano. El 24 de febrero lanzó la proclama "Por la fe y por la patria" y comenzaron las acciones. Pero el zar lo desautorizó y dio seguridades al Sultán de que Rusia mantendría sus relaciones de amistad. "La indecisión de Alejandro Ipsilandis, las diferencias étnicas entre griegos, rumanos, serbios y búlgaros; los desacuerdos de los líderes; la actitud sospechosa y finalmente traicionera de Vladimirescu ${ }^{1}$ y de Savvas²; la envidia

1 Teodoro Vladimirescu, militar valaco que se unió al movimiento y mostró enseguida una actitud sospechosa que terminó en abierta traición.

2

Fokianós Sabbas, poderoso "combatiente" que traicionó, pasándose a las fuerzas turcas. 
entre los jefes griegos, producto principal de su desmedido egoísmo; el feroz enlodamiento de los demás; la indisciplina de los soldados irregulares y la falta de dedicación a sus deberes, como era natural perjudicaron su unidad y su moral y los disolvieron incluso antes de que entraran en contacto con el enemigo [...]. La catástrofe de Moldovalaquia provino del golpe más terrible e irremediable: la descomposición desde dentro"”.

El heroísmo no faltó en el alzamiento frustrado. El 7 de junio, en la derrota que destruyó el ejército de Ipsilandis, cayeron más de 200 jóvenes del llamado Batallón Sagrado, en Dragatsanion. A su sacrificio dedicó el poeta Andreas Kalvos una de sus más conmovedoras Odas. Diez días después se autosacrificó en Skuleni Atanasio Karpenisiotis. Los últimos combatientes, Yorgakis Olimpios y Yanis Farmakis en inmolaron en el monasterio de Sekos en el mes de septiembre.

Mientras, en Grecia, luego de varios triunfos menores, precisamente el 23 de septiembre cae en poder de los griegos la ciudad capital del Peloponeso, Tripolitsá. Es el primer gran triunfo de la Revolución, que se había iniciado en marzo. El alzamiento, largamente preparado por la Filikí Hetería ${ }^{4}$, encuentra sus primeras dificultades en organizar a combatientes que en gran parte sólo tienen la experiencia de la lucha guerrillera y que son reacios a la disciplina. Uno de ellos, Teodoro Kolokotronis, se entrega a la tarea de tratar de poner orden. Contribuye igualmente a esta labor Demetrio Ipsilandis, hermano del desdichado príncipe Alejandro5.

Las divisiones, los celos, los egoísmos, las ambiciones, pondrán un duro sello a la Revolución, lo que contrasta con el general idealismo de los filohelenos. Otro sello de la Revolución griega fue el inmenso movimiento filohelénico que rápidamente se organizó en toda Europa, incluso en Estados Unidos. Y no sólo se trató de apoyar con armas y provisiones a los

3 Vacalópulos, Ap. (1995) Historia de Grecia Moderna 1204-1985, p. 141.

4 La Filikí Hetería Sociedad de la Amistad fue fundada en 1814, en Odesa, por Nicolás Skufás, Atanasio Tsakalof, P. Anagnostópulos y Emanuel Xanthos, con el objetivo de preparar el alzamiento armado que debía liberar a Grecia. Funcionó como un organismo estrictamente secreto. En 1820 aceptó su jefatura el príncipe Alejandro Ipsilandis. Se decidió iniciar la revolución en los Principados Danubianos, a cuyo territorio penetró Ipsilandis, desde suelo ruso, cruzando el río Pruthos.

Alejandro Ipsilandis, tras penetrar en territorio austriaco, fue puesto en prisión. Las condiciones en que se lo mantuvo minaron su salud. Liberado el 24 de noviembre de 1827, murió el 31 de enero del año siguiente. Había nacido en 1792, hijo de Constantino Ipsilandis, príncipe de Moldovalaquia. Habia hecho una brillante carrera militar en Rusia, distinguiéndose en las guerras napoleónicas. 
revolucionarios, sino que de las más diversas latitudes surgió una legión de hombres dispuestos a entregar sus vidas por la libertad de la Hélade. La figura más señera es Lord Byron, quien murió en Mesolonyi en abril de 1824. En todo el mundo, incluida Latinoamérica se escribieron poemas sobre el combate de los griegos ${ }^{6}$. Otro sello de la Revolución griega fue el temprano y perseverante esfuerzo por organizar un régimen democrático, en medio de la lucha. Ya el $1^{\circ}$ de enero de 1822 se vota en las regiones liberadas la primera Constitución, titulada "ley Orgánica", aprobada por la primera Asamblea Nacional, en diciembre de 1821. Las Asambleas Nacionales de Astros (1823) y de Trezene (1827) contemplan igualmente un régimen republicano y democrático.

Las tensiones entre Teodoro Kolokotronis, representante en cierto modo de los tradicionales guerrilleros, los kleftes, y Alejandro Mavrokordatos, típico político, de familia fanariota, y sus partidarios llevan a las dos guerras civiles de 1824.

No pocos desastres dejan una terrible estela de sangre y destrucción: la derrota de los filohelenos en Peta, el 4 de julio de 1822; la matanza de Quíos ${ }^{7}$, el 2 de abril del mismo año, en la que 30 mil griegos fueron degollados y 45 mil hechos prisioneros para ser vendidos como esclavos; la matanza de Psará, el 21 de julio $^{8}$, que dejó desierta a la isla; el éxodo de Mesolonyi, el 10 de abril de 1826.

La Revolución pasará por momentos de gran peligro, con las derrotas que le propinan las fuerzas invasoras de Mechmet Drámali en 1822; y después las de Ibrahim Pachá, enviado por Mohamed Pacha, virrey de Egipto, por orden del Sultán. La intervención de Ibrahim, que comenzó en febrero de 1825, dejó una terrible estela de destrucción y muerte.

En abril de1827, la Asamblea Nacional de Trezena, elige como primer Gobernante a Ioanis Kapodistrias, quien asume al año siguiente, después que en la batalla naval de Navarino, 20 de octubre de ese año, las flotas de Inglaterra, Francia y Rusia destruyeran la armada turca. Esa batalla fue el preludio de la guerra entre Rusia y Turquía, que comenzó en 1828. "Turquía fue vencida y obligada por el Tratado de Adrianóplis a reconocer la autonomía de Grecia (1929). La diplomacia rusa triunfaba en los Balcanes, pues la liberación de

6 Ver Latorre Broto, E. (2020) "Contribuciones al estudio del filohelenismo en Hispanoamérica: Cantos a la Grecia libre en la Gran Colombia”. Byzantion Nea Hellás $N^{\circ}$ 40-2020. Hubo también expresiones de filohelenismo en poetas mexicanos, cubanos y argentinos.

7 Famoso se hizo el cuadro de Delacroix "La matanza de Quios".

8 Tanto Dionisio Solomós como Andreas Kalvos dedicaron conmovedores versos a la Catástrofe de Psará. 
Grecia aparecía ligada a la victoria de las armas rusas. Era justamente lo que Gran Bretaña quería evitar. A propuesta de su ministro Aberdeen, un nuevo protocolo de Londres (febrero 1830) declaró estado independiente a Grecia, bajo una monarquía hereditaria".

La noble figura de Kapodistrias se destaca en medio de las pasiones y ambiciones que enfrentó su corto gobierno. Como ya anotamos, cae asesinado en Nauplio el 27 de septiembre de 1831.

El sello de las divisiones que caracteriza la heroica Revolución de 1821 ofrece su rostro más feroz después de la muerte de Kapodistrias: en la anarquía.

Con tintes terribles la describe Nicolás Dragumis:

"Si un curioso incursiona en la historia de la lucha por la independencia buscando tiempos paralelos a los que prevalecían ese año [1832], no tardará en convencerse de que jamás hubo un embrollo de pasiones, disputas, motines, venganzas, guerras intestinas, administraciones ilícitas, asambleas más ilegales, intromisiones extranjeras, ofensas a la dignidad nacional, envilecimiento de personalidades públicas y privadas, confiscaciones de los derechos del pueblo, saqueo de los bienes públicos, una confusión, digo, como la que ocurrió tras la muerte del Gobernante, jamás, ni bajo las circunstancias más atroces, dominó a Grecia [...]. Quien arrebatar primero el poder a fin de estar en posesión de él al arribo del rey, fue el supremo propósito por le cual luchaban los charlatanes de la nación - por una parte -, destruyendo a la propia nación - por otra. Y apareció otra vez la multitud amorfa y de nuevo sentó dominio la abominable anarquía" ${ }^{\circ}$.

\section{La influencia francesa en el estallido de la Revolución}

Otro de los precursores, Adamandios Koraís es acaso quien mejor ha aclarado los conceptos respecto de la influencia francesa en el despertar nacional griego que llevó a la Revolución. Después de detallar diversos aspectos del movimiento de la Ilustración de Grecia, movimiento al que califica de "revolución moral", expresa:

"La Revolución Francesa llega al fin y no deja, como se debía esperar de ella, de dar un nuevo impulso a la revolución moral, ya

9 Svoronos, N. G. (1972) Histoire de la Grèce Moderne, pp. 44-45.

10 Citado por Vacalópulos, Ap. (1995), p. 174. 
comenzada entre los griegos ${ }^{11}$; impulso tanto más fuerte cuando que estaba acompañada de la esperanza de un mejoramiento de un mejoramiento de la suerte de Grecia"12.

En 1825, Koraís destaca el carácter de la causa de los griegos y hace ver sus diferencias con los objetivos de la Revolución Francesa:

"Repito: la causa de los griegos no es igual a la de la Revolución Francesa [...]. Las revoluciones en la Europa ilustrada se hacen por una parte del pueblo contra los demás; pero en Grecia todos están de acuerdo contra el conquistador extranjero. Durante la Revolución [Francesa], se trataba de transformar ésta o aquella institución del país. En Grecia debe construirse todo desde el principio [...]. La Revolución Francesa debía decidir sobre 1a forma de gobierno, mientras que aquí la guerra debía decidir sobre la existencia de toda una nación"13.

\section{Rigas Velestinlís: su lucha y su martirio}

Rigas nació en 1757 en el pueblo de Velestino, en Tesalia, cerca de la antigua Ferai. De ahí que algunos historiadores lo nombraron como Rigas Fereos. Pero él se dio por nombre Rigas Velestinlís y también Rigas Tesalós, es decir Tesaliense. Poco o nada se conoce de su niñez y primera juventud. En sus escritos, la única alusión a sus estudios es este pasaje, en el que explica por qué utilizó la "lengua sencilla", $\alpha \pi \lambda$ ov́v úpos. En su obra Florilegio de Física, editada en 1790: "La causa de que por qué utilicé la lengua simple fue para no provocar en los demás con la oscuridad del griego arcaizante lo que yo mismo padecí cuando estudiaba".

En 1768, cuando comienza la guerra ruso-turca, Rigas tiene 11 años. Seguramente participaría de las esperanzas de liberación de los griegos esclavizados, cuando en 1770, la escuadra rusa aparece en el Egeo y se inicia la llamada "Revolución de Orlov". Y también tuvo que ser testigo de las feroces represalias de los turcos después de la derrota y el retiro de las fuerzas rusas del Peloponeso. Por eso, al referirse a las bárbaras represiones de los otomanos, sus palabras en su Proclama de 1797, no son retóricas: “¡Cielo: tú eres testigo imparcial de semejantes crímenes! ¡Sol: tú ves cada día esos

\section{Subrayado nuestro.}

12 Koraís, A. (1983) Mémoire sur l'état actuel de la civilisation dans la Grèce, p. 60.

13 Koraís, A. (1983) Dialogo de dos griegos sobre los intereses helénicos. 
salvajes atentados! ¡Tierra: tú recibes incesantemente los ríos de sangre inocente!"

Ya a los veinte años, se encuentra en Constantinopla, donde acrecienta su cultura y su conocimiento de lenguas. Se sabe que hacia $1785^{14}$ trabajó como "gramatikós", secretario, del príncipe Alejandro Ipsilandis, quien había sido "hospodar", "hegemón", gobernador, del Principado semiautónomo de Valaquia. Así lo afirma Ioanis Filimón: "Tenía entonces en Constantinopla Alejandro Ipsilandis como secretario a Rigas Fereos, a cuya formación contribuyó con toda su paternal disposición" ${ }^{15}$. De la amplia cultura de Rigas nos da testimonio el historiador Johan Christian Engel ${ }^{16}$. En su obra Historia de la nación húngara y de los países limítrofes, escribe a propósito de una de las grandes obras de Rigas, los Mapas, lo siguiente:

"Cuán agradable me ha sido el haber conocido a un tesaliense del sector de la vieja Servitsa. Este hombre se encuentra ahora en Viena y su nombre es Regas, que los griegos actuales pronuncian Rigas. Posee conocimientos literarios y políticos y conoce, además de la lengua del lugar, el alemán, el francés y el italiano. Ha viajado durante seis años por las provincias turcas con el fin de darnos mejores mapas que los existentes - por ejemplo el de Choiseul -, junto con una geografía estadística e histórica de las regiones que ha recorrido. De los 24 mapas que en total debe editar y que serán grabados por la mano maestra del grabador Müller de Viena, en gran formato y maravilloso papel, pero con el texto totalmente en lengua neogriega- con las denominaciones nuevas y antiguas de las ciudades -, cuatro están listos y se venden en la imprenta de los hermanos Pulios [...]. El primer mapa de la serie comprende Constantinopla y sus alrededores, con una maravillosa vista de esta ciudad. Los otros mapas muestran en una serie la Grecia antigua y serán bien recibidos tanto por los políticos como por los filólogos" ${ }^{\prime 17}$.

14 Filimón, I. (1859), reproducción s/f) Ensayo histórico sobre la Revolución Griega, vol.II, p. 10. Reproducido en la serie Obras Completas de Clásicos Neogriegos. 15 Ibid., p. 8.

16 J. Ch. Engel, 1770-1814, historiador alemán nacido en Hungría. Vivió largo tiempo en Viena donde fue conocido como filoheleno.

17 Citado por P. Enepekidis (1965) Rigas-Ipsilandis.Kapodistrias Investigaciones en los archivos de Austria, Alemania, Italia, Francia y Grecia, pp. 33-34. 
En Viena, Rigas desarrolla una intensa actividad literaria y editorial. En 1790 aparecen dos obras: Escuela de los amantes delicados ${ }^{18}$, seis relatos de Restif de la Bretonne, traducidos por él, y Florilegio de física para los griegos inteligentes y amantes del saber seleccionado de las lenguas alemana y francesa por Rigas Velestinlís Tesaliense, editado con gastos suyos para provecho de los compatriotas. En el prólogo, leemos diversas consideraciones sobre sus motivaciones: "Siendo yo por naturaleza patriota, no me he contentado sólo con lamentar la situación de mi Nación, sino que me he esforzado por ofrecer un aporte [...], seleccionado de la lengua alemana y francesa los elementos más esenciales de la Historia Natural". Al final de esa nota prologal, insiste en que su idea ha sido "contribuir a la recuperación de la decaída nación griega" 19 .

En la última página de la Física, Rigas anuncia que ha traducido $E l$ espíritu de las leyes de Montesquieu, la que "al terminarse, debe imprimirse". Tal edición no llegó a realizarse y el texto de la traducción se ha perdido. Tal vez la censura imperial detuvo su publicación.

En 1791, Rigas regresa a Bucarest, donde pasa cinco años, durante los cuales dedica buena parte de su tiempo a la preparación de su gran obra: los Mapas. Eran una serie de 24 cartas geográficas, de las cuales la mayor es la Carta de la Hélade. A mediados de 1796, Rigas está en Viena, donde aparece el primero de los mapas: Plano de Constantinopla, de su golfo y de su estrecho, de su vista desde Stavrodromi, con sus denominaciones antiguas y modernas, por Rigas Vlestinlís Tesalienses, editado en favor de helenos y filohelenos. Sigue a comienzos de 1796 el Mapa general de Moldavia...Y enseguida aparece la magna obra cartográfica y patriótica de Rigas: Carta de la Hélade, en el que se contienen sus islas y sus numerosas colonias en Asia Menor [...] en un corpus de 12 secciones, editada por primera vez por Rigas Velestinlís Tesaliense, en favor de helenos y filohelenos.

La Carta de la Hélade es una obra maestra de la cartografía, producto de un largo y paciente trabajo y de un intenso amor por Grecia y su cultura. Es una verdadera hazaña del arte del dibujo y del arte tipográfico. Demuestra inmensos conocimientos de geografía y de arqueología y traduce un conmovedor afán pedagógico. Se trataba de mostrar a "helenos y filohelenos" lo que había sido y era la Hélade. De ahí que Rigas haya acumulado una cantidad increíble de elementos: planos de ciudades y lugares; nombre antiguos y modernos;

18 La traducción es bastante libre. Incluso, Rigas incorpora pasajes suyos y canciones. Por ello, se ha visto en ella una obra casi original, y Victoria HetziyeoryíuHassioti la ha considerado "la primera novela de amor neogriega". 
fechas y nombres de batallas; catálogo de emperadores bizantinos; dibujos de monumentos; figuras de monedas antiguas..., etc" ${ }^{20}$.

La actividad editora el año 1797 es intensa. Aparece el Viaje del joven Anacarsis a Grecia del Abate Barthélemy, los tres primeros tomos en traducción del estudiante Georgios Sakelarios; el cuarto en parte en traducción de Rigas y en parte de otro joven patriota, Georgios Vendotis. Circulan también ese año Trípode moral, traducción métrica hecha por Rigas del drama Olimpia de Metastasio,; su traducción de La Pastora de los Alpes de Marmontel; y El primer marino, idilio de Gessner, vertida por Antonio Koroniós, quien será uno de los siete mártires que morirán junto a Rigas.

Casi junto con los Mapas, alcanzó Rigas a editar la Imagen de Alejandro Magno, con lecturas en griego y en francés, que terminan con la frase "Publié par Rigas Velestinlis Thesalien, en faveur des Grecs et des amis de la Grèce". El rostro de Alejandro está al centro de la lámina y lo rodean cuatro imágenes de sus "hazañas" y las efigies de los generales Casandro, Ptolomeo, Antígono y Seleuco ${ }^{21}$.

A mediados de año, impulsado por el fervor libertario general entre los griegos de Viena, reforzado acaso por los éxitos de Napoleón en Italia, mirado hasta entonces como libertador, Rigas concibe un plan revolucionario y escribe y edita sus últimas obras: el volumen Nuevo Gobierno Político de los habitantes de Rumelia, Asia Menor, islas del Mediterráneo y Vlajomoldavia, que contenía el Thurios, la Proclama, la Constitución de la República Helénica y Los Derechos del Hombre y otro volumen con su traducción del Manual del Arte de la Guerra y normativas del general Khevenhüller, un "Catecismo democrático" y dos" Canciones revolucionarias".

Los dos últimos libros de Rigas contenían, pues, todo su ideario y todos los instrumentos ideológicos y teóricos para la causa de la insurrección y luego el establecimiento de un estado independiente, democrático y multinacional. Enepekidis sostiene que el "Mapa se hizo en estrecha labor conjunta con la del Manual militar, complementaba a éste y debía ser utilizado por los primeros oficiales del primer ejército griego como una especie de mapa de Estado Mayor". ${ }^{22}$

20 Los Mapas de Rigas se reproducen en la edición de Vranusis en la serie de Obras Completas de los Clásicos Neogriegos, vol. II, pp. 573-664, reducidos, naturalmente. Como anexo al volumen Estudios sobre Rigas Velestinlís de Nicólaos Pandazópulos, se reproduce la Carta de la Hélade, encartado, aunque en reducción.

21 La Imagen de Alejandro Magno se reproduce en la edición mencionada en la nota anterior, vol. II, p. 667. En las pp. 668-671, se reproducen detalles y los textos de la Imagen.

P. Epenekidis, o. cit., p. 30. 
Estos últimos impresos fueron embalados y enviados a Trieste, consignados a la casa comercial de Antonio Niotis. Rigas escribió a Antonio Koroniós, otro patriota del grupo, para que retirara el cargamento. Pero Koroniós se había ausentado de Trieste y la carta llega a manos de su socio Demetrio Ikonomos. Éste la abrió, retiró las cajas, las abrió y las entregó a la policía. Rigas el $1^{\circ}$ de diciembre había obtenido pasaporte para viajar. Llegó a Trieste el 19 de ese mes y fue inmediatamente detenido. Comenzaron las detenciones de los otros complotados. El 30 de diciembre se le pusieron grilletes para ser enviado a Viena, viaje que comenzó el 5 de febrero de 1798 . El proceso fue largo y lleno de penalidades para los patriotas detenidos. La conclusión del Ministro del Interior fue que los hechos "no constituían delito" dentro del Imperio Austríaco, pero que "la influencia de sus acciones e ideas seria maligna en los territorios imperiales". Los prisioneros no ocultaron su amor a la libertad de Grecia, posiblemente porque no imaginaron que serían entregados a los turcos. En las Actas del proceso, por ejemplo, se lee: "Confiesa Rigas que siempre ha deseado la liberación de Grecia del yugo turco y que, después de la salvación de su alma, tiene como primer anhelo el ver expulsados de Grecia a los turcos; y añade que si hoy se tratara de llegar a la rebelión en Grecia, él estaría listo para cooperar"23.

El cristiano emperador Francisco decidió entregar a 8 prisioneros al Sultán, a sabiendas que serían martirizados y finalmente ejecutados. El 10 de mayo fueron recibidos en Belgrado por las autoridades turcas. En las mazmorras de la Torre Benoisa, los ocho "infieles" pasaron cuarenta días de martirio para ser estrangulados en la misma celda el 24 de junio. Sus cadáveres fueron arrojados al río Danubio. Los nombres de los mártires eran: Rigas (40 años), Efstratios Argendis (31años), Antonio Koroniós (27 años), Demetrio Nikolidis (32 años).Ioanis Karatzás (31 años), Theojaris G. Turuntzias (22 años, Ioanis Emanuel (24 años) y su hermano Panayotis Emanuel (22 años).

Conmueven las palabras con que Koraís recuerda a los mártires. Escribe que al saber la noticia del martirio de los ocho patriotas, sintió que dentro de él" la Hélade toda, con lágrimas en los ojos" le dictaba estas palabras:

"Recientemente, el emperador de Alemania, aunque atormentado por una dolorosa y mortal enfermedad, que debiera siquiera enseñarle el amor y la simpatía al ser humano, entregó inmisericordemente al tirano de la Hélade a ocho griegos; ocho griegos que buscaban pacíficamente los medios adecuados para ilustrar a sus compatriotas y liberarlos del yugo de la esclavitud, han sido martirizados en la flor de la edad la noche del 24 de 
junio de 1798. Se vierte la generosa sangre griega de sus venas y vuelan sus almas benditas a reunirse con las inolvidables almas de los que han muerto por la Libertad [...]. ;Este derramamiento de sangre inocente en vez de atemorizar a los griegos más bien los moverá a venganza! ${ }^{24}$,

La resonancia de la obra y del sacrificio de Rigas fue "realmente enorme en extensión y en profundidad e inagotable en duración histórica. La figura del Protomártir era el símbolo que buscaban la fe y la conciencia de los griegos subyugados. Con el primer lugar en el santuario de los corazones, su figura se revistió con algo de la luz de los santos y el fulgor de los profetas" ${ }^{25}$. Y Daskalakis sintetiza así la significación de la acción de Rigas: "Incomparable bardo de la libertad [...], el más noble visionario de los ideales humanos [...], el primer luchador y Protomártir del renacimiento de la nación helénica, y, también, el primer heraldo de la emancipación, fraternización y pacífico convivir de los pueblos balcánicos"26.

\section{La idea de la libertad}

Para Rigas, como para Koraís y Vúlgaris, la idea de la libertad se entronca con su nacimiento en la Grecia Antigua. La tradición griega, el lazo nunca interrumpido de la lengua y la cultura griegas, es elemento básico en la voluntad de recuperar la libertad para su pueblo. Si bien es verdad que las ideas filosóficas francesas se habían propagado de un modo u otro por toda Europa, y por lo tanto también en los territorios sojuzgados por el Imperio Otomano, no es menos cierto que para los griegos cultos los ideales de la Ilustración europea y luego de la Revolución Francesa no eran sino el revivir de aquellas fuerzas morales y espirituales que habían guiado a la Grecia Antigua a su grandeza.

Para Rigas, la cultura griega no constituye sólo un bien universal, patrimonio de todos los hombres, sino que al mismo tiempo es algo enteramente propio. Esa cultura es la gran creación de sus antepasados. Él y sus compatriotas habitan la misma tierra donde se creó esa cultura. Y en

24 Koraís, A. (1798, 1983) Adelfiki didaskalia, París 1798, Reedición facsimilar, pp. IV-V. En la primera edición, después de la frase "ocho griegos que...", Koraís escribió "Se presentan a esta misma hora ante el tirano estos valerosos mártires de la libertad; quizás a esta misma hora baja sobre sus sagradas cabezas el puñal del verdugo. Se vierte la generosa sangre griega..."

25 Vranusis, L. (1963) "Introducción” a Rigas Velestinlís 1757-1798, p. 105.

26 Daskalakis, Ap. (1979) Rigas Velestinlís Planes revolucionarios y martirio final, p. 6 . 
la misma 1engua que ellos hablan se formularon, casi dos milenios y medio antes, los ideales humanistas, las ideas de libertad y democracia que inspiran la acción del Precursor. En su Proclama, Rigas destaca el hecho de que sus compatriotas deben ser dignos de sus gloriosos antepasados.

Los mapas de Rigas y su Imagen de Alejandro Magno, con los nombres antiguos y modernos de lugares y ciudades; con sus referencias a hechos, hombres, instituciones y cultura griegas de la Antigüedad y de la época bizantina, muestran cómo en sus propósitos se une el afán de destacar la relación directa e ininterrumpida de los griegos contemporáneos con los antiguos, la admiración por la cultura clásica y 1a identificación de los ideales humanistas clásicos con sus ideales libertarios y democráticos. La misma idea se puede apreciar en su entusiasmo por el Viaje del joven Anacarsis y su propósito de publicar la traducción existente y de completar la parte que faltaba, así como en su idea de colocar notas al texto de Barthélemy. Mencionemos también el hecho de que en la bandera que Rigas diseña para la República Helénica, y que describe en un anexo a la Constitución, aparece como primera figura la "maza de Heracles". Se combina ella con la Cruz; y de este modo se representa la unión del mundo clásico con el cristiano.

Pensamos que es justo decir que la idea de la libertad en los Precursores no proviene del ejemplo de la Revolución Francesa. Todos admiran, aman y estudian la historia antigua y la cultura clásica. Koraís y Rigas acuden a ella para ejemplificar la libertad, la dignidad y la democracia. En su Himno patriótico, Rigas invoca a las grandes figuras del helenismo antiguo para que vean cómo luchan sus descendientes:

Estrofa 33: Alejandro, sal ahora / de la tumba para ver / otra vez la valentía / grande de los macedonios / que a los enemigos vencen / ¡con alegría en el fuego! Estrofa 34 Que Leonidas reviva / junto a sus trecientos bravos / para ver al espartano / como un corcel arrojarse: / devora, pisa y destroza a los turcos, ¡oh valientes! ${ }^{27}$.

Como muchos griegos, Rigas había vuelto primero sus ojos hacia Rusia y Austria, cuando los dos imperios cristianos hacían la guerra contra el Imperio Otomano. Las esperanzas puestas tradicionalmente en la Rusia ortodoxa y que habían sufrido una trágica frustración en 1770, habían vuelto a despertarse a raíz de la nueva guerra ruso-turca. Pero esta vez la contienda no se limitó a los tradicionales rivales (ésta era la tercera guerra ruso-turca en el siglo XVIII). Otro "imperio cristiano" aunque no ortodoxo, estaba también contribuyendo 
al decaer de 1a potencia otomana. Pero una vez más las esperanzas de los pueblos oprimidos de los Balcanes, y más concretamente las de los griegos, se vieron frustradas. De acuerdo con sus respectivos intereses, las potencias cristianas firmaron la paz en los tratados de Sistov, en agosto de 1791, y de Jasi, en enero de 1792. Terminó así la "guerra de los tres imperios". Sólo entonces, como lo afirma Vranusis, "podemos hablar de un giro político de Rigas". Y más aún, como agrega este estudioso, "debe aparecer más tarde Napoleón para dar alas con sus victorias a las expectativas nacionalistas de Rigas y sus compatriotas" 28 .

Por otra parte, hay que tener en cuenta, como ya anotamos, que los ideales humanistas de la Francia revolucionaria constituían un verdadero revivir de los ideales espirituales de la antigua Grecia. Por eso, tenían que coincidir también con las convicciones que se había formado Rigas, el cual, bastante antes de la Revolución Francesa, había nutrido su alma con una profunda admiración por los valores de la cultura clásica. G. K. Vlajos, en el estudio "La idea griega en el proyecto de Adamandios Koraís y de Rigas Fereos", examina con detalle el tema de la filiación de las ideas libertarias del Precursor Rigas ${ }^{29}$.

\section{El plan de Rigas y los franceses}

La relación concreta de Rigas y sus planes con los franceses tiene que ver con el avance de Napoleón hacia el este de Europa. La llegada de las tropas francesas a territorio griego, a las Islas Jónicas, a fines de junio de 1797, dio un matiz casi de inminencia a la posibilidad de que la Francia revolucionaria apoyara una insurrección en Grecia. Es entonces cuando Rigas escribe a Napoleón, a través del cónsul francés en Trieste. Lo hace días después del desembarco e n Corfú - Kérkira - de los franceses, comandados por Gentily.

El texto de una copia de esa carta, que se adjuntó al proceso de Rigas, no ha sido hallada; pero hay referencias a ella en las actas de los interrogatorios. El prisionero no podía negar su escrito. Reconoce que "sin recibir ninguna orden, escribió, como en nombre de todos los griegos, en julio del año pasado, la carta incluida aquí bajo el número 5, escrita por su mano al cónsul de Francia en Trieste [...]. Dice [Rigas] que el contenido substancial de esta carta al cónsul es la petición de todos los griegos a él para que intervenga ante el General [Bonaparte], que comanda el ejército francés en Italia, y 1e ruegue dé ayuda

28 Vranusis, L. (1973,, op. cit., p. 46

29 VIajos, G. K. (1994) "La idea griega en el proyecto de Adamandios Koraís y de Rigas Fereos", Hiperia, II 
para la lucha de aquellos" ${ }^{\prime 30}$.

La policía dice que Rigas escribió esta carta "con ocasión de la proclama dada a conocer públicamente por los franceses". Se trata, sin duda, de la proclama de Gentily al desembarcar en Corfú. Interesa el texto de este documento, porque el comandante francés al dirigirse a los griegos invocaba no los principios de la Revolución Francesa, sino el lazo que unía al pueblo griego con sus antepasados y a las instituciones republicanas creadas por los antiguos. Las palabras del comandante galo, dirigidas al pueblo helénico e impresas en griego, italiano y francés, parecían contener, también, la promesa de un respaldo concreto a una revolución libertadora en Grecia:

"iQue rebroten en vosotros las virtudes de vuestros antepasados! ¡Devolved al nombre de los griegos su primer brillo y gloria, haciendo que recupere su antigua fuerza y energía!". Los franceses dicen venir a ofrecer libertad "a los descendientes del primer pueblo ilustrado por instituciones republicanas". Había en la proclama expresiones rotundas, que ponían nuevamente esperanzas en el pueblo esclavizado: "Francia defenderá y preservará con toda su fuerza los derechos que tenéis". "Os prometo grandes e importantes beneficios en nombre del general Bonaparte y de la República de los Franceses, que es aliado natural y asistente de todos los pueblos libres" ${ }^{\prime 3}$.

El clima de efervescencia libertaria que existía entre los griegos tenía que verse exaltado por el hecho de que las fuerzas que se veían como libertadoras pisaran ya tierra griega, aunque ésta fuera precisamente la única no dominada por los turcos- el Heptaneso. Uno de los seguidores de Rigas, el joven Filipo Pétrovits - y que debe haber tenido 17 o 18 años, refleja este clima y el convencimiento de que la revolución era posible, en las cartas que dirigió al Abate Sieyès, miembro del Directorio y poco después presidente de la Asamblea Nacional Francesa. Gaspar Peters, profesor de francés, otro de los enjuiciados y después desterrado, le ayuda a traducir sus cartas. En la primera, de 17 de julio de 1797, leemos estas expresiones:

“¡Famosos franceses, gloriosa nación! Sois los benefactores de toda la humanidad y enemigos jurados de los tiranos. Esta es la razón, ciudadano Director, por la cual nos dirigimos a

$30 \quad$ Legrand, É., op. cit., p. 65.

31 De esta proclama trilingüe de Gentily hay un ejemplar en la Biblioteca Genadios, en Atenas. En fotografía la publica D. Petrakakos en Historia parlamentaria de Grecia, I, pp. 137-139. 
vosotros. Somos los descendientes de aquellos mortales que en la Antigüedad fueron los primeros en las obras del espíritu, como lo sois ahora vosotros, los franceses. ¡Somos griegos!”

Más adelante, el muchacho habla de las anteriores desilusiones de los griegos, de las esperanzas puestas en rusos y austriacos, y frustradas; y reafirma finalmente la voluntad libertaria de sus compatriotas. Pero necesitan la ayuda de Francia, pues temen que Rusia intervenga en contra de ellos, y no podrían hacer frente, a la vez, a dos poderosos enemigos:

"Por eso, os ruego de parte de mi nación que nos ayudéis [...]. ¡Los griegos queremos ser libres como nuestros antepasados! [....] Os aseguro, padre Sieyès, que en pocos días podemos provocar una gran revolución. En cuanto estalle 1a revolución, tomaremos con pocas fuerzas dos o tres ciudades y, hecho esto, toda Grecia empuñará la espada de la venganza para derribar al tirano!"32.

Como lo anota Vranusis, es posible que la conmovedora carta de este muchacho refleje también el contenido de la carta de Rigas a Napoleón, cuyo texto se perdió. Se reivindica la condición de descendientes de los antiguos helenos que tienen los griegos modernos y el hecho de que ellos en la época antigua crearon las instituciones republicanas y democráticas. Se afirma con fuerza la voluntad libertaria y la decisión revolucionaria. Se expresa desconfianza y temor respecto de Rusia, que tantas esperanzas había defraudado.

Pero ni Pétrovits ni Rigas ni sus compañeros alcanzaron a saber que Napoleón y, por lo tanto, Francia, habían ya abandonado su posición, al menos, oral, de apoyo a la libertad de Grecia.

Como lo expone detalladamente Ap. V. Daskalakis, el movimiento revolucionario que pretendía iniciar Rigas muy difícilmente hubiera podido tener éxito, pues no sólo no habría contado con ayuda francesa, sino que tampoco habría sido posible en corto tiempo lograr que los elementos armados del pueblo griego - los maniates, los kleftes y los suliotas - se incorporaran a una contienda generalizada. Esas fuerzas cuando actuaban lo hacían localmente y en forma de guerrillas. Después de examinar los posibles planes que Rigas tuviera en mente cuando parte hacia Trieste, Daskalakis resume así el valor de

32 Los conmovedores textos de estas dos cartas se reproducen, como documentos anexos a los interrogatorios de Rigas y sus compañeros, en Amandos, C. (1977) Documentos inéditos sobre Rigas Velestinlis, pp. 125-127 y 137-139. 
las acciones del gran Precursor:

"Rigas Velestinlís fue el primero que pensó y hasta cierto punto se atrevió a la aplicación real de un amplísimo plan de revolución liberadora del helenismo, realizada con sus propias fuerzas. Por más que fueran atrevidos, hasta quizás temerarios, por más que fueran impracticable en la realidad sus planes revolucionarios, fueron con todo algo completamente nuevo en la historia del pueblo griego sometido a los turcos y dieron las bases para posteriores esfuerzos para la organización de un combate libertador pannacional. Por otra parte, las reflexiones sobre lo posible o imposible del éxito del intento proyectado por Rigas, reflexiones que formulamos hoy los historiadores se basan en antecedentes que no eran asequibles en aquella época" ${ }^{33}$.

\section{La Constitución de Rigas y su importancia}

Sin perjuicio de consagrar los derechos del ciudadano en su Constitución, Rigas escribió un documento con el título Los derechos del hombre y la Proclama, en que llamaba a la insurrección contra el despotismo del Imperio Otomano. La Constitución es republicana y democrática y posee mucha semejanza con la Constitución francesa de 1793, modificada en 1795, aunque con notables e inteligentes adaptaciones a la realidad de los pueblos balcánicos. Los Derechos del Hombre constituyen un documento muy interesante, que sigue en parte a la Declaración de los derechos del hombre y del ciudadano de Francia, pero no sólo con adaptaciones al mundo de los pueblos balcánicos, sino también con una serie de complementos de tipo pedagógico.

Los territorios que serían liberados del dominio otomano, en un caso, y español en el otro, tenían algunas características semejantes y otras diferentes en cuanto a su población. La República Helénica, como nombra Rigas al nuevo estado, abarcaría los territorios poblados por griegos, pero no sólo ésos, es decir la Grecia europea propiamente tal, sino que integrarían ese estado diversos otros grupos nacionales: valacos y moldavos (rumanos), albaneses, serbios, turcos, armenios y otros; y en cuanto a religiones, estarían representadas la cristiana, la musulmana y la hebrea. Los habitantes de esas extensas regiones convivirían en perfecta igualdad de derechos y en plena libertad religiosa, continuando así la convivencia de siglos bajo la servidumbre. Pero ahora lo harían en libertad.

33 Daskalakis, Ap. V. (1979) Planes revolucionarios y martirio final de Rigas Velestinlis, p. 94-95 
Comunes son los derechos y sus garantías; los enumerados en Los derechos del hombre y los detallados en la Constitución; comunes los deberes, contrapartida de los derechos; común la lengua griega, lo que en cierta proporción correspondía a la realidad en la época de Rigas. Salvo en este punto, en el de la lengua general, acerca de la cual no hay en la Constitución otra norma, la diversidad de raza, religión e idiomas que coexisten en la República Helénica, se reitera en varias disposiciones. Así, el artículo 7, que encabeza el párrafo titulado "Sobre la soberanía del pueblo", expresa: "El pueblo soberano son todos los habitantes de este reino, sin excepción de religión y de lengua: griego, búlgaros, albaneses, vlajos, armenios, turcos y todo otro tipo de raza".

G. K. Vlajos destaca el mérito de Rigas al enfrentar "el problema de la organización de un Estado multinacional sobre bases democráticas de igualdad de derechos". Y agrega: "Como era natural, se necesitó mucho esfuerzo y gran habilidad de parte de Rigas para construir un marco constitucional válido, justamente en razón del hecho de que se debía conciliar la soberanía popular con la pluralidad de los grupos étnicos del Imperio otomano, sin que se perjudicara, de acuerdo con la revolucionaria idea del estado-nación, la demanda primordial de la igualdad y hermandad de todos los pueblos. Rigas lo logra, teóricamente al menos, de un modo admirable, fortaleciendo el derecho de los pueblos del reino a la diferencia, sin disminuir la unidad fundamental del poder, mientras que, al mismo tiempo, incorporando o también enriqueciendo las proclamas francesas en su Constitución, erige barreras protectoras de los derechos de los individuos y de las etnias contra posibles transgresiones por parte del gobierno" 34 .

Así pues, el Estado que concibe Rigas es un Estado multinacional y multirracial, pero unitario, aunque con amplias garantías para los distintos grupos racionales, étnicos y religiosos. Los integrantes de los tres poderes son elegidos por votación popular. El poder se genera a través de las elecciones ordinarias, pero también a través del plebiscito, al que pueden convocar los ciudadanos al margen de la voluntad de las autoridades ya elegidas ${ }^{35}$.

34 G. K. Vlajos: "La idea griega en el proyecto de Adamandios Koraís y de Rigas Fereos" (en griego), en Hiperia II, Atenas, 1994, pp. 541-542.

35 El texto de la Constitución de Rigas en Obras Completas (en griego), al cuidado de L. I. Vranusis, 2 vols, Atenas, s. f. y en Obras revolucionarias (en griego), al cuidado de D. A. Karaberópulos, Ediciones de la Sociedad Científica de Estudios Feré-VelestinoRigas, Atenas, 1994. Una traducción castellana de Christos Clair-Vasiliadis, en Byzantion Nea Hellás, 3-4, Santiago, 1973-1974, pp. 344-371. Un análisis de la obra de Rigas y en especial de su Constitución en M. Castillo Didier: Dos Precursores Miranda y Rigas América Grecia, Centro de Estudios Griegos, Bizantinos y Neohelénicos, Universidad de Chile, Santiago, 1998. 
El articulado de la Constitución de Rigas es detallado y con una clara tendencia pedagógica en su forma de redacción, en la que se intercalan ejemplos. Además, hay diversos artículos de forma declarativa, como el número 28, que consagra la flexibilidad de la Constitución y de las leyes.. En el plano de las relaciones del Estado con otras naciones, los artículos 118 y 120 declaran que "Los griegos reciben a todos los extranjeros que han sufrido injusticia y a todos los exiliados de su patria por causa de la libertad. Se niegan a recibir y atender a los tiranos".

\section{La Proclama de Rigas}

Reproducimos la Proclama del Precursor en la que con fogosas palabras llamaba a la insurrección para terminar con la tiranía extranjera.

\section{Proclama revolucionaria por las leyes y la Patria}

El pueblo, descendiente de los helenos, que habita Rumelia, Asia Menor, las Islas del Mediterráneo y Valaquia y todos los que gimen bajo la insoportable tiranía del odioso despotismo otomano o fueron obligados a irse a otros países para salvarse de su yugo intolerable, todos, digo, cristianos y turcos, sin distinción de religión (porque todos son creaturas de Dios e hijos del Primer Creador), pensando que el tirano llamado sultán se ha entregado completamente a sus sucios deseos mujeriles, se ha rodeado de eunucos y de sanguinarios e ignorantes cortesanos, ha olvidado y despreciado la humanidad, su corazón se ha endurecido contra la inocencia, y el más hermoso país del mundo, que es elogiado en todas partes por los sabios, se ha convertido en un desorden repugnante, tanto que nadie, de cualquier clase o religión, está ya seguro de su vida ni de su honor ni de sus bienes; el más tranquilo, el más inocente, el más honesto ciudadano corre en cada momento el peligro de convertirse en una desgraciada víctima de la imaginación del tirano o de los salvajes gobernadores y las indignas autoridades del tirano, o por último (lo que sucede con más frecuencia) de sus malvados imitadores, quienes gozan con el crimen impune, con la más cruel inhumanidad, con el asesinato, sin distinción alguna, sin proceso alguno.

¡Cielo: tú eres testigo imparcial de semejantes crímenes! ¡Sol: tú ves cada día esos salvajes atentados! ¡Tierra: tú recibes incesantemente los ríos de la sangre inocente! ¿Qué boca puede decirme lo contrario? ¿Quién es ese tigre que estaría de acuerdo con tantas iniquidades? Que se presente y encontrará como testigo contrario a toda la creación, que gime en silencio por los injustos ríos de sangre humana derramada. 
Este pueblo, digo, hasta ahora infeliz, dándose cuenta de que todas sus penalidades y dolores, sus lágrimas cotidianas, su perdición, provienen del mal e indigno gobierno, de la carencia de buenas leyes, ha decidido, alzándose de una vez, mirar hacia el cielo, levantar valientemente su cuello sobrecargado $\mathrm{y}$, armando poderosamente sus brazos con las armas de la venganza y de la desesperación, proclamar en voz alta ante la humanidad toda, con voz tremenda, sus santos y sagrados derechos, que le fueron obsequiados por la divinidad para vivir tranquilamente sobre la tierra.

Entonces, para que todos los habitantes puedan unánimemente juzgar siempre con ojos vigilantes los movimientos del gobierno, de los que gobiernan, con el fin de que legislen para la sociedad, sacudiendo honrosamente el mezquino yugo del despotismo y abrazando la preciosísima libertad de sus gloriosos antepasados; que no se dejen pisotear jamás como esclavos por la inhumana tiranía; que cada uno tenga como brillante espejo ante sus ojos los fundamentos de la libertad, seguridad y felicidad; que los jueces sepan muy claramente cuál es su deber indiscutible para con los ciudadanos, y que los legisladores y primeros (en la jerarquía) del gobierno conozcan la norma más correcta, según la cual su oficio se debe ajustar a la prosperidad de los ciudadanos, se proclama brillantemente la siguiente declaración pública de los valiosos derechos del hombre y del libre habitante de este país"36.

\section{REFERENCIAS BIBLIOGRAFICAS}

AMANDOS, C. (1977) Anékdota éngrafa perí Riga Velestinlí Documentos inéditos sobre Rigas Velestinlís, Atenas. Reed. Sociedad Científica de Estudios Feré-Velestino-Rigas.

ANYELU, A. (1990) “O Volteros ke i Hélines loyii tu 18u eona" Voltaire y los sabios griegos del siglo XVIII, Mélanges offerts à Roger Milliex pour ses cinquante années de présence grecque, ELIA.

BÁDENAS DE LA PEÑA, P. (2003) "El programa revolucionario del Turios". En López Villalba, M.: Traducir la Revolución La Nueva Constitución Política de Rigas de Velestino. Madrid: C. S. I. C.

CAMARIANO C., A. (1967) "Les iles Ioniennes de 1797 à 1807 et l'essor du courant philofrancais parmi les Grecs". Praktiká tu Tritu Panioníu Sinedriu Actas del III Congreso Panjónico, Atenas.

CAMARIANO, N. (1980) "Rhigas Velestinlis Compléments et corrections concernant sa vie et son activité", Revue des Études SudEst Européennes, t. XVIII-1980, $\mathrm{N}^{\circ} 4$.

$36 \quad$ El texto en Obras Completas de Rigas Velestinlis (2000). Volumen V. Edición de P. M. Kitromilidis, pp. 33-35. 
CLAIR-VASILIADIS, CH. (1975) "Rigas Velestinlís (1757-1790) Protomártir de la libertad y democracia helénicas", Byzantion Nea Hellás, $\mathrm{N}^{\circ} 3-4$, Santiago) Centro de Estudios Bizantinos y Neohelénicos Univers.

DASKALAKIS, AP. Y. (1977) 0 Rigas Velestinlís hos Didáskalos tu Yenus Rigas Velestinlís como Maestro de la Nación. Atenas: Ed. E. G. Vayionakis.

--- (1979) Riga Velestinlí epanastatiká sjedia ke martirikón telos Planes revolucionarios y martirio final de Rigas Velestinlís. Atenas: Ed. E. G. Vayionakis.

--- (1977) Ta ethneyertiká tragudia tu Riga Velestinlí Los cantos patrióticos de Rigas Velestinlís. Atenas: Ed. E. G. Vayionakis.

--- (1976) To politevma tu Riga Velestinli Proton Síndagma Helinikís Dimokratías ke eleftheras diavióseos ton valkanikón laón $\mathrm{El}$ régimen político de Rigas Velestinlís Primera Constitución de una República Helénica y de vida libre de los pueblos balcánicos. Atenas: Ed. E. G. Vayionakis.

DIMARÁS, K. TH. (1985) 0 neohelinikós diafotismós La ilustración griega, 4a. ed.. Atenas: Ed. Hermís.

DRULIA, L. (1977) I polisimía ton simvolon ke to 'rópalon tu Hirakleus'tu Riga, La polisemia de los símbolos y la 'maza de Heracles' de Rigas, Eranistís, t. 21, 1997 (Atenas).

ENEPEKIDÍS, P. K. (1965) Rigas-Ipsilandis-Kapodistrias Érevne is ta arjía tis Afstrias, Yermanis, Italias, Galias ke Heladas Rigas-IpsilandisKapodistrias Investigaciones en los archivos de Austria, Alemania, Italia, Francia y Grecia. Atenas.

FILIMÓN, LOANIS (s.f.) Dokimion historikón perí tis helinikis Epanastáseos Ensayo histórico acerca de la Revolución griega (según ed. 1859). Reimpr. en Obras Completas de los Clásicos Neogriegos, Atenas, s.f.

FINLAY, G. (1971) History of the Greek Revolution and the Reign of King Otho, Oxford, 1877. Reed. Londres:Zeno Booksellers..

KARABERÓPUlOS, D. AP. (1997) Ónoma ke katagoyí tu Riga Velestinlí Nombre y origen de Rigas Velestinlís. Atenas: Ed. Sociedad Científica de Estudios Feré -Velestino- Rigas..

--- (1998) "Thurios: to hieróteron asma tis filís mas" Thurio: el canto más sagrado de nuestra raza, en el vol. Thurios Versiones musicales tradicionales y melodías prerrevolucionarias, 2a. ed. Atenas: Ed. Sociedad Científica de Estudios Feré-Velestino-Rigas, Atenas.

KEPHALLINEOU, E. (1989) "The influence of the French Revolution on prerevolutionary modern greek poetry (1789-1821)". Atenas: Actas del VI Congreso Internacional de Estudios del Sudeste Europeo.

KITROMILIDIS, P. (Ed.) (2010) Adamantios Korais and the European Enlightenment. Oxford: Voltaire Foundation. 
--- (1991) “I politikí skepsi tu Evyeníu Vúlgari” El pensamiento político de Eugenio Vúlgaris. Argostoli: Actas del V Congreso Panjónico (1986).

--- (1989) “La Révolution Francaise dans le Sud Est de l'Europe”, en el vol.

La Révolution Francaise et l'Hellénisme Moderne, Atenas.

KOKINOS, D. I Heliniki Epanástasis La Revolución Griega, 6a. ed. Atenas: Ed. Melisa.

KONDILIS, P. (1988) Oneohelinikós diafotismós I filosofikés idees La ilustración neogriega Las ideas filosóficas. Atenas: Ed. Themelio.

KORAÍS, A. (1983) Adelfiki didaskalía Enseñanza fraternal. Atenas: Reed. facsimilar del Archivo Griego Literario e Histórico, ELIA.

--- (1983) Perí ton helinikón simferondon diálogos dío Grekón Diálogo de dos Griegos sobre los intereses helénicos. Atenas: Ediciones del ELIA.

LEGRAND, É. (1996) Anékdota éngrafa perí Riga Velestinli ke ton sin aftó martirisandon ek ton en Vieni arjíon exajthenda ke dimosiefthenda hipo Emiliu Legrand Meta metafráseos helinikís hipó Spirídonos P. Lambru Documentos inéditos sobre Rigas Velestinlís y los con é1 martirizados, extraídos de los archivos e Viena y publicados por Émile Legrand Con traducción griega de Spiridón P. Lambros, Atenas, 1891. Atenas: Reed. Sociedad Científica de Estudios Feré-Velestino-Rigas.

NOUTSOS, P. (2001) «La 'Nouvelle Administration Politique' de Rhigas Dimension sociale et politique de la citoyenneté de ses membres».Eranistís 23.

PANDAZÓPUlOS, N. (1994) Meletímata páno ston Riga Velestinlí Estudios sobre Rigas Velestinlís Atenas: Ed. de la Sociedad Científica de Estudios Feré-Velestino-Rigas.

PAPARRIGÓPULOS, C. (1955) Historía tu helenikú ethnus Ékdosis hévdomi ikonografimeni, metá prosthikon, simióseon ke veltióseon epi ti vasi ton neoteron historikón dedomenon hipó Niku A. Vei Historia de la nación helénica Séptima edición ilustrada con complementos y mejoras sobre la base de los supuestos históricos modernos por Nikos Veis. Atenas: Ed. Seferlis.

PERAlES, M. A. (1990) Rigas Velestinlís, Precursor de la Independencia de Grecia, Tesis de Licenciatura, inédita. Santiago: Universidad de Chile. Contiene la primera traducción del Thurio al español.

PETRADAKOS, D. (1935) Kinovuleftiki historía tis Helados Historia parlamentaria de Grecia. Atenas.

RIGAS VELESTINLÍS (s. f.) Apanda Obras Completas. Col. Obras Completas de Clásicos Neogriegos.Atenas: Ed. L. I. Vranusis, 2 vols.

--- (1975) "Nueva administración política de los habitantes de Rúmeli, Asia Menor, Islas del Mediterráneo y Valaquia-Bogdanía", trad. Ch. ClairVasiliadis, Byzantion Nea Hellás, ํㅜ 3-4. (Santiago). 
--- (1994) Ta epanastatiká Epanastatiki prokírixi Ta díkea tu anthropu To Síndagma 0 Thurios Patriotikós Himnos Las obras revolucionarias Proclama revolucionaria Los derechos del hombre La Constitución El Thurio Himno patriótico. Atenas: Ed. Sociedad Científica de Estudios Feré-Velestino-Rigas.

--- (1998) Thurios Paradosiakés musikés paraloyés ke proepanastatikés melodies Thurio Versiones musicales tradicionales y melodías prerrevolucionarias. Atenas: Ed. Sociedad Científica de Estudios FeréVelestino-Rigas, 2a. ed.

SPENTZAS, S. (1994) "Prosényisi stin ikonomikí ke dimosionomikí skepsi tu Riga” Aproximación al pensamiento económico y financiero de Rigas, Hiperia, II.

SVORONOS, N. (1972) Histoire de la Grèce Moderne. .Paris: Presses Universitaires de France.

STAVRÓPULOS, TH. (1994) "I ámesi dimokratía sto polítevma tu Riga Fereu" La democracia directa en el régimen político de Rigas Fereos, Hiperia, II.

VAKALÓPULOS, AP. (1995) Historia de Grecia Moderna 1204-1985, trad., notas, cuadros, imágenes, índices A. Zorbas y N. Nicolaides. Santiago: Centro de Estudios Bizantinos y Neohelénicos Universidad de Chile.

--- (1971) Historía tis Helinikis Epanastáseos tu 1821 Historia de la Revolución Griega de 1821. Atenas.

VARIOS AUTORES (1971-1977) Historia tu helinikú ethnus Historia de la nación helénica. Atenas: Ekdotikí Athinón, 14 vols.

VAYENÁS K. TH. (1954) "loanis Karatzás, o síndrofos tu Riga Fereu" Ioanis Karatzás, el compañero de Rigas Fereos: Atenas: Jroniká tis Kipru Agones ton Kiprion yia tin elefthería, Anales de Chipre Combates de los chipriotas por la libertad.

VIAJOS, G. K. (1994) “I helinikí idea ston politikó sjediasmó tu Adamandíu Koraí ke tu Riga Fereu" La idea griega en el proyecto político de Adamandio Koraís y de Rigas Fereos, Hiperia, II.

VRANUSIS, L. (1994) “Agnosta neaniká jirógrafa tu Riga” Manuscritos juveniles desconocidos de Rigas, Hiperia, II.

--- (s. f.) "I pnevmatikí fisiognomía tu Riga" La fisonomía espiritual de Rigas, introd. a Apanda Obras Completas de Rigas,.

--- (s. f.) "Isagoyí" ston tomo Rigas Érevna, sinagoyí ke meleti Introducción al volumen Rigas Investigación, recopilación y estudio, Vasikí Vivliothiki, Atenas, s.f.

--- (1992) I simea, to ethnósimo ke i sfrayida tis Helinikís Dimokratías tu Riga La bandera, el escudo y el sello de la República Helénica, apartado del tomo VIII de Deltíon Heraldikis ke Yenealoyikis Heterías Helados. Atenas: Boletín de Heráldica y Genealogía de Grecia. 
--- (1990.) “Rigas ke Marmontel » Rigas y Marmontel, Helino-Galiká Melanges offerts à Roger Miliex.Atenas. Ediciones del ELIA.

--- (1963) Rigas Velestinlís 1757-1798. 2a. ed. aumentada, Atenas: Vasikí Vivliothiki.

ZORAS G. TH. (1965) Proepanastatikí períodos (Rigas, Vilarás, Jristópulos) Período prerrevolucionario (Rigas, Vilarás, Jristópulos). Atenas: Ed. E. Vayionakis. 